\title{
Nanoscale
}

(D) Check for updates

Cite this: Nanoscale, 2019, 11, 19278

Received 15th May 2019,

Accepted 10th July 2019

DOI: $10.1039 / \mathrm{c} 9 \mathrm{nr} 04142 \mathrm{~g}$

rsc.li/nanoscale

\section{Functionalization and patterning of nanocellulose films by surface-bound nanoparticles of hydrolyzable tannins and multivalent metal ions $\uparrow$}

\author{
Mukta V. Limaye, (iD) *a,b,c Christina Schütz, (iD) ${ }^{a, b}$ Konstantin Kriechbaum, (iD ${ }^{a}$ \\ Jakob Wohlert, ${ }^{\mathrm{b}}$ Zoltán Bacsik, ${ }^{\mathrm{a}}$ Malin Wohlert, ${ }^{\mathrm{b}}$ Wei Xia, (D) ${ }^{\mathrm{d}}$ Mama Pléa, \\ Cheick Dembele, ${ }^{e}$ German Salazar-Alvarez ${ }^{a, b}$ and Lennart Bergström ${ }^{\star a}$
}

Inspired by the Bogolanfini dyeing technique, we report how flexible nanofibrillated cellulose (CNF) films can be functionalized and patterned by surface-bound nanoparticles of hydrolyzable tannins and multivalent metal ions with tunable colors. Molecular dynamics simulations show that gallic acid (GA) and ellagic acid (EA) rapidly adsorb and assemble on the CNF surface, and atomic force microscopy confirms that nanosized GA assemblies cover the surface of the CNF. CNF films were patterned with tannin-metal ion nanoparticles by an in-fibre reaction between the pre-impregnated tannin and the metal ions in the printing ink. Spectroscopic studies show that the $\mathrm{Fe}^{\mathrm{III} / \mathrm{II}}$ ions interact with GA and form surface-bound, stable GA-Fe ${ }^{\text {III/II }}$ nanoparticles. The functionalization and patterning of CNF films with metal ion-hydrolyzable tannin nanoparticles is a versatile route to functionalize films based on renewable materials and of interest for biomedical and environmental applications.

Patterning and dyeing of textiles and paper has been used by humankind for millennia for artwork and writing. Indeed, all human civilizations have developed distinct dyeing or patterning techniques based on available organic and inorganic materials ${ }^{1-4}$ examples include Woad and Indigo dyes, ${ }^{1,2}$ Maya blue, ${ }^{5}$ Egyptian pigments, ${ }^{3,6}$ and oil paints used in Buddhist paintings. ${ }^{4}$ Interestingly, some dyes or pigments are ubiquitous to civilizations around the world. An important example

\footnotetext{
${ }^{a}$ Department of Materials and Environmental Chemistry, Arrhenius Laboratory, Stockholm University, SE-106 91 Stockholm, Sweden. E-mail: mvlimaye@gmail.com, lennart.bergstrom@mmk.su.se

${ }^{b}$ Wallenberg Wood Science Center, Royal Institute of Technology, SE-100 44 Stockholm, Sweden

${ }^{c}$ Department of Physics, Indian Institute of Science Education \& Research, Berhampur 760010, Odisha, India

${ }^{d}$ Department of Engineering Sciences: Applied Materials Science, The Angström Laboratory, SE-751 21 Uppsala, Sweden

${ }^{e}$ Laboratoire de Physico-chimie des Matériaux, Université des Sciences, des Techniques et des Technologies de Bamako, BP E 2306, Mali

$\dagger$ Electronic supplementary information (ESI) available: Materials and methods, Fig. S1-S9 and tables. See DOI: 10.1039/c9nr04142g-
}

of such a dye is the black or dark blue or brown iron-tannin dyes, which have been documented in Egyptian, European, Indian and Chinese cultures. ${ }^{6-9}$ Although the recipes for the specific techniques may differ between regions and cultures, the dyeing process always involves the combination of a tannin-rich and an iron-rich source to produce a dark, insoluble complex that can be used to pattern and dye both cellulose- and protein-based textiles. ${ }^{2,7,10}$ The Bogolanfini mud cloth dyeing technique from West Africa differs significantly from other iron-tannate dyeing techniques not only with respect to the sources of the tannins and the iron but also because a two-step procedure involving pre-adsorption of tannins, primarily gallic acid (GA), and ellagic acid (EA) before the pattern is applied using a viscoelastic, iron-rich mud. ${ }^{11-14}$

The patterning of paper and cellulose-based substrates is important not only for printing and dyeing but also for rapidly evolving applications such as paper-based diagnostics, actuators and sensors. ${ }^{15-17}$ The patterning of e.g. waxes onto paper is commonly used to guide the transport of small amounts of liquid, and inkjet-printed conductive inks are used for electronic applications. Recent reports have demonstrated that metal-tannic acid networks can be assembled into hollow capsules or used for surface modification and coatings. ${ }^{18-20}$ However, reports on the patterning of cellulose-based substrates using renewable and Earth-abundant materials are sparse. Inspired by the in-fiber formation of insoluble dyes in the traditional Bogolanfini mud cloth dyeing technique, we report how nanocellulose films can be functionalized and patterned by nanoparticles of hydrolyzable tannins and multivalent metal salts. Gallic acid adsorbs and assembles onto the surface of the nanocellulose and forms dark, surface-bound nanoparticles when exposed to iron ions. The patterning of free-standing nanocellulose films with multifunctional metaltannin nanoparticles is a simple and versatile process based on renewable and Earth-abundant materials. This work is an example of how understanding the chemistry of the historically and culturally important Bogolanfini dyeing technique 
enabled the development of a novel and versatile patterning technique, primarily based on organic materials derived from trees and abundant metal ions.

Nanocellulose films ${ }^{21}$ display a combination of high strength and flexibility, and are useful in applications ranging from gas diffusion barriers to energy storage and sensors. ${ }^{22-25}$ Here, we have prepared free-standing films from a dispersion of carboxylated cellulose nanofibrils (CNF), a hydrolyzable tannin, e.g. GA, and an iron $\left(\mathrm{Fe}^{\mathrm{III}} / \mathrm{Fe}^{\mathrm{II}}\right)$ salt solution (see Tables $\mathrm{S} 1$ and $\mathrm{S} 2 \uparrow$ for details). The addition of an iron salt solution to a mixture of GA and CNF resulted in the immediate formation of dark GA-Fe ${ }^{\mathrm{III} / \mathrm{II}}$ complexes ${ }^{26-29}$ and drop-casting a dispersion of $\mathrm{CNF}$ with $\mathrm{GA}-\mathrm{Fe}{ }^{\mathrm{III} / \mathrm{II}}$ complexes resulted in functionalized free-standing films (Fig. 1a). The CNF can also be functionalized by nanoparticles of iron salts and other hydrolyz- able tannins, e.g. EA, tannic acid (TA), and mixtures of GA, EA and TA (Fig. S1 $\dagger$ ). The method of functionalization is also applicable to (enzymatic) nanocellulose films without surface carboxyl groups (Fig. S2 $\dagger$ ).

Tapping mode atomic force microscopy (AFM) showed that the addition of GA resulted in the formation of assemblies that covered the nanofibrillar surface of the neat CNF (Fig. 1b and c). The topographic image suggests that these assemblies were $20-50 \mathrm{~nm}$ in size, and the negligible difference in contrast in the height image indicates that the CNF is homogeneously coated with GA assemblies. Fig. 1d shows that addition of both $\mathrm{GA}$ and $\mathrm{Fe}^{\mathrm{III}}$ salt results in a formation of surface-bound nanoparticles with a size of 20-50 $\mathrm{nm}$.

We have performed Molecular Dynamics (MD) simulations to study the interaction and assembly of GA onto a cellulose a)

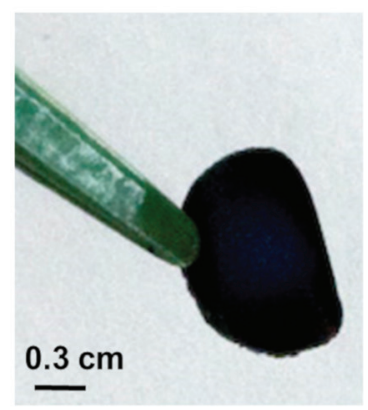

c)

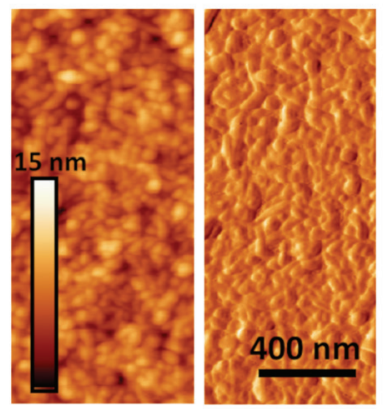

e)

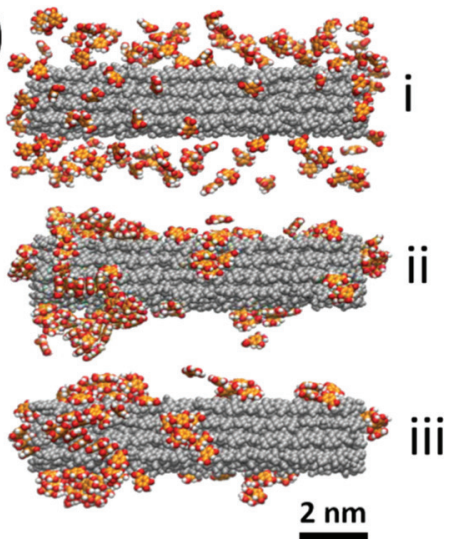

b)

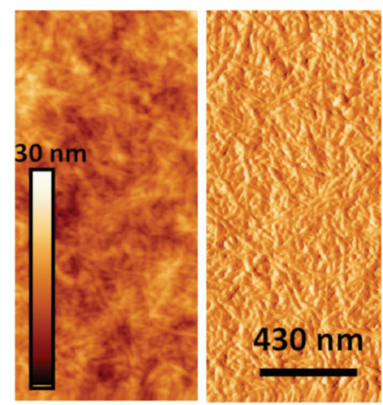

d)
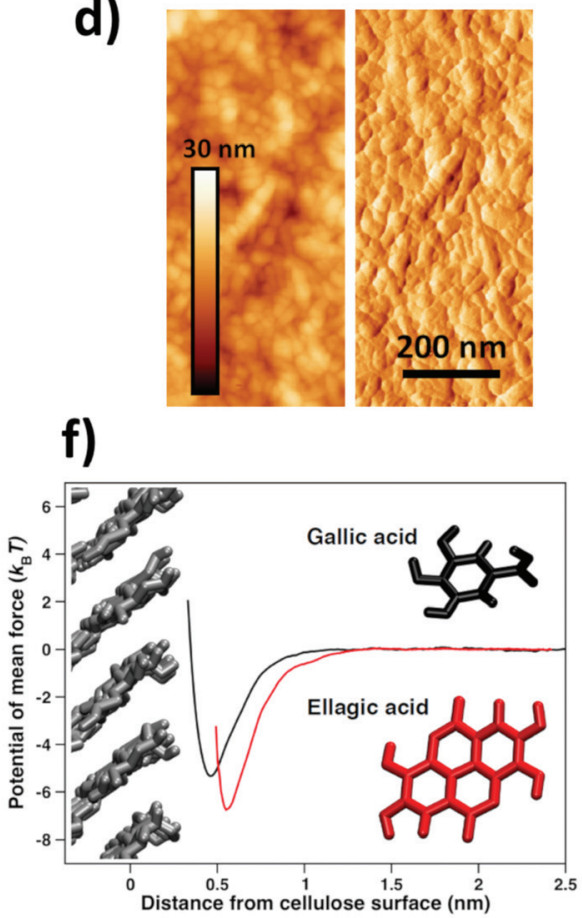

Fig. 1 Functionalization of nanocellulose nanofibril (CNF) films by gallic acid (GA)-Fe'II complexes. (a) Photograph of free-standing CNF film impregnated with GA and Fe"l' salt. Tapping mode topographic atomic force microscopy (AFM) height (left) and amplitude images (right) of films of: (b) CNF; (c) CNF which has been subjected to a GA solution; (d) CNF that has been subjected to solutions of GA and Fe ${ }^{\text {III }}$ salt. (e) Molecular dynamic simulations of GA assembling on crystalline cellulose surface at: (i) short time; (ii) intermediate time and (iii) after 50 ns. (f) Energy diagram of GA and ellagic acid (EA) interacting with nanocellulose. 
surface. Fig. 1e(i) shows that GA adsorbed quickly on the nanocellulose surface and that the adsorbed GA immediately started to assemble (Fig. 1e(ii)). The surface-bound GA assemblies rapidly grew in size and the amount of adsorbed polyphenolic monomers decreased until essentially all the GA had assembled into relatively large assemblies (Fig. 1e(iii)). Hence, the simulations corroborate the formation of surface-bound GA assemblies, as shown by the AFM measurements (Fig. 1c). The flat ring structure of the adsorbed GA assemblies at steady-state (Fig. 1f) is a feature polyphenols share with cellulose-binding dyes, which often contain a significant amount of benzene rings. ${ }^{30}$ This is also true for carbohydrate-binding proteins, which are usually rich in residues featuring aromatic side chains. ${ }^{31,32}$ The affinity (Fig. If and Fig. S3†) between these flat structures and carbohydrates has primarily been attributed to van der Waals and hydrophobic interactions as the aromatic ring structures stack on top of the pseudo-flat surfaces of the hexopyranose rings, ${ }^{30-32}$ possibly assisted by hydrogen bonds. ${ }^{32}$ From the MD simulations, it is evident that stacking is pronounced also between the GA molecules, suggesting that hydrophobic interactions play an important role in the formation of surface-bound assemblies. In contrast, previous work on complexation of $\mathrm{Fe}^{\mathrm{III}}$ and $\mathrm{TA}$ showed that $\mathrm{TA}-\mathrm{Fe}{ }^{\mathrm{III}}$ primarily form monolayers on different substrates. ${ }^{18,19,33,34}$ Hence, whereas TA $\left(\mathrm{C}_{76} \mathrm{H}_{52} \mathrm{O}_{46}\right)$ and $\mathrm{Fe}^{\mathrm{III}}$ ions can form thin metal-phenolic networks, ${ }^{19,34}$ the ability of $\mathrm{GA}\left(\mathrm{C}_{7} \mathrm{H}_{6} \mathrm{O}_{5}\right)$ to stack onto the cellulose surface results in the formation of nanosized $\mathrm{GA}-\mathrm{Fe} \mathrm{eII}^{\mathrm{IIII}}$ nanoparticles.

We have investigated the interactions between CNF, tannins and iron by a combination of infrared spectroscopy (IR), X-ray absorption near edge spectroscopy (XANES) and X-ray photoelectron spectroscopy (XPS) of CNF films with surface-bound tannins and tannin- $\mathrm{Fe}^{\mathrm{III} / \mathrm{II}}$ species. The difference IR spectrum obtained by subtracting the contribution of untreated (neat) CNF from the spectrum of CNF treated with GA is a convenient way to visualise differences between absorbed and free GA (Fig. 2a). We observe that the $\mathrm{C}=\mathrm{O}$ infrared band present at $1698 \mathrm{~cm}^{-1}$ in free $\mathrm{GA}^{35}$ is shifted to $1686 \mathrm{~cm}^{-1}$ for the adsorbed GA in the difference spectrum, which suggests that the carboxylic acid group of GA is at least partially involved in the interaction with the CNF surface. The IR spectrum of CNF coated with $\mathrm{Fe}^{\mathrm{III} / \mathrm{II}}-\mathrm{GA}$ complexes showed a very broad band in the 1530 to $1780 \mathrm{~cm}^{-1}$ region (Fig. $2 \mathrm{~b}$ ). The $\mathrm{C}=\mathrm{O}$ band at $1686 \mathrm{~cm}^{-1}$ present in the $\mathrm{CNF}$ film with pre-adsorbed GA
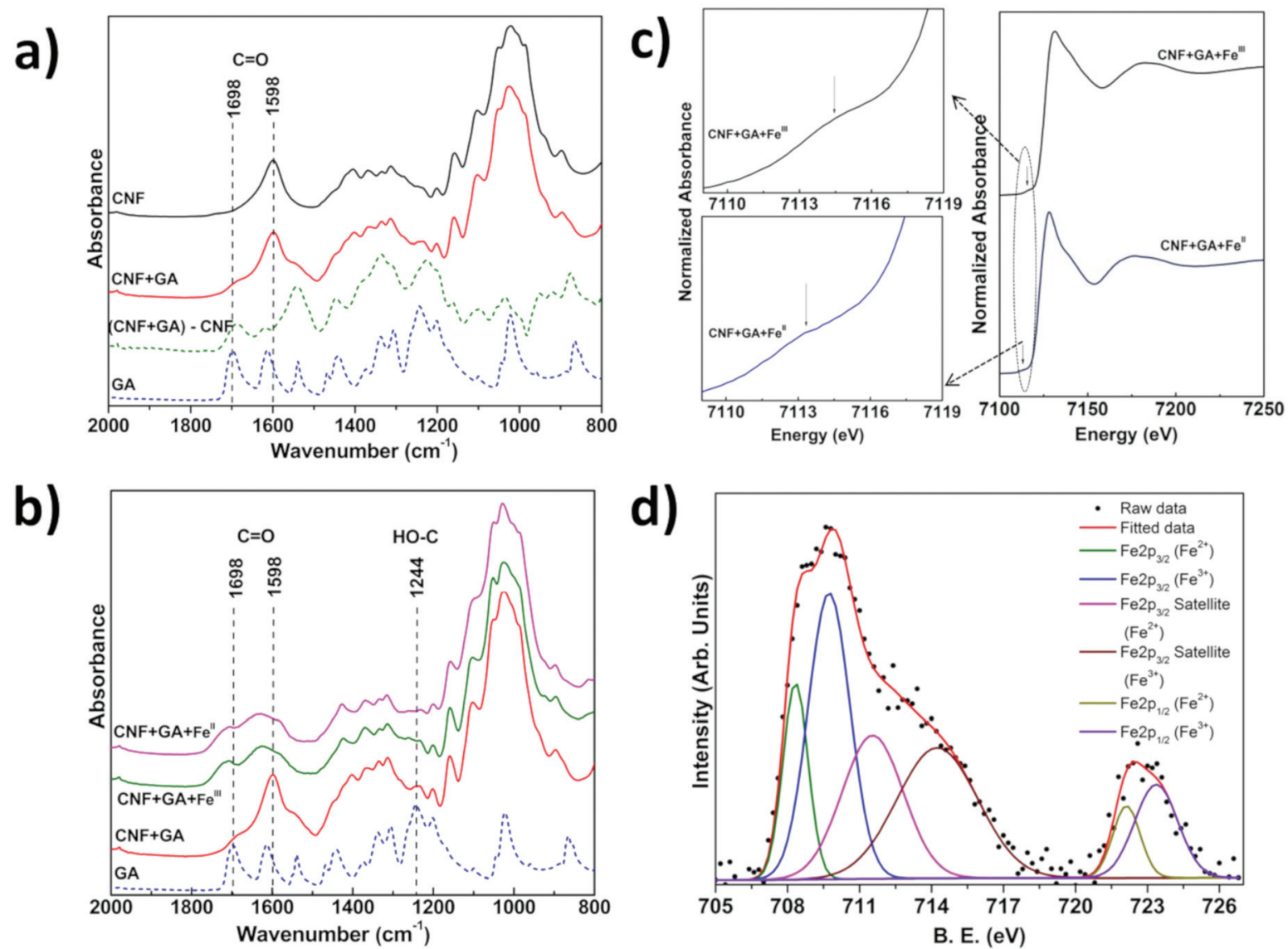

Fig. 2 Spectroscopy of films of cellulose nanofibrils (CNF) functionalized with tannin-iron complexes. Infrared spectra of: (a) GA, neat CNF film, and CNF film which has been subjected to a GA solution; (b) CNF film which has been subjected to solutions of GA and Fe"l' or Fe" salts. (c) XANES spectra of CNF which has been impregnated with solutions of GA and Fe ${ }^{\prime \prime \prime}$ or Fe $\mathrm{e}^{\text {II }}$ salts with magnified pre-edge feature. (d) Core-level XPS spectra of the $\mathrm{Fe} 2 p$ of a CNF film impregnated with solutions of GA and a Fe" salt. 
shifted to higher wavenumber at $1707 \mathrm{~cm}^{-1}$ after addition of $\mathrm{Fe}^{\mathrm{III} / \mathrm{II}}$. The $1598 \mathrm{~cm}^{-1} \mathrm{C}=\mathrm{O}$ stretching vibration band present in $\mathrm{CNF}$ and GA-treated CNF (Fig. S4†) disappeared and was replaced by an absorption peak at $1629 \mathrm{~cm}^{-1}$ after addition of $\mathrm{Fe}^{\mathrm{III} / \mathrm{II}}$. In addition, the reduced intensity of the HO-C stretching band $\left(\sim 1244 \mathrm{~cm}^{-1}\right)$ with respect to free GA indicates that the phenolic groups of GA form complexes with iron ions. Similar changes were observed by Guo et al. ${ }^{18}$ in an IR study of complexes of $\mathrm{Fe}^{\mathrm{III}}$ and TA. The absorption peaks at $1582 \mathrm{~cm}^{-1}$ and $1427 \mathrm{~cm}^{-1}$ that evolve after addition of Fe-ions can be attributed to coordinated $\mathrm{COO}^{-}$asymmetric and symmetric stretching modes, respectively. The separation between the two peaks/features is $\sim 155 \mathrm{~cm}^{-1}$ which is consistent with the $\mathrm{Fe}^{\mathrm{III}}$ and $\mathrm{COO}^{-}$interaction previously observed in $\mathrm{Fe}^{\mathrm{III}}-\mathrm{GA}$ complexes. ${ }^{26,36}$ No change in the IR spectra was observed after washing the films several times with water, which suggests that the $\mathrm{Fe}^{\mathrm{III} / \mathrm{II}}-\mathrm{GA}$ nanoparticles were strongly bound to the CNF surface.

XANES measurements on CNF films impregnated with GA and $\mathrm{Fe}^{\mathrm{II}}$ and $\mathrm{Fe}^{\mathrm{III}}$ ion salts (Fig. 2c) displayed weak pre-edge features at $\sim 7113$ and $\sim 7114 \mathrm{eV}$ respectively, which represented the $1 \mathrm{~s} \rightarrow 3 \mathrm{~d}$ electron transition. ${ }^{37-39}$ The $\mathrm{Fe}$ K-absorption edge for CNF films treated with $\mathrm{GA}$ and $\mathrm{Fe}^{\mathrm{II}}$ and $\mathrm{Fe}^{\mathrm{III}}$ salts was observed at $\sim 7128.5 \mathrm{eV}$ and $7130 \mathrm{eV}$, respectively, which for both $\mathrm{Fe}^{\mathrm{II}}$ and $\mathrm{Fe}^{\mathrm{III}}$ systems represent the $1 \mathrm{~s} \rightarrow 4 \mathrm{p}$ electron transition (Fig. 2c). ${ }^{37-39}$ The deconvolution of XANES pre-edge features indicated that iron was present in a mixed oxidation state i.e. iron was present as $\mathrm{Fe}^{\mathrm{II}}$ as well as $\mathrm{Fe}^{\mathrm{III}}$ in $\mathrm{CNF}$ films impregnated with $\mathrm{GA}$ and $\mathrm{Fe}^{\mathrm{III}}$ or $\mathrm{Fe}^{\mathrm{II}}$ salts (Fig. S5 $\dagger$ ). ${ }^{38}$ The relative intensity of the deconvoluted $\mathrm{Fe}^{\mathrm{II}}$ and $\mathrm{Fe}^{\mathrm{III}}$ peaks of the Fe $2 \mathrm{p}$ core level XPS spectra showed that the ratio of $\mathrm{Fe}^{\mathrm{III}} / \mathrm{Fe}^{\mathrm{II}}$ was 1.3 and 1.5 in CNF-film impregnated with GA and $\mathrm{Fe}^{\mathrm{II}}$ and $\mathrm{Fe}^{\mathrm{III}}$, respectively (Fig. 2d, Fig. S7 \& Table S3†). The XANES and XPS investigations thus showed that Fe was present as both $\mathrm{Fe}^{\mathrm{II}}$ and $\mathrm{Fe}^{\mathrm{III}}$, irrespective of whether $\mathrm{Fe}^{\mathrm{II}}$ or $\mathrm{Fe}^{\mathrm{III}}$ salt was initially added to the GA-CNF materials.

The C 1s core level XPS data (Fig. S7 \& Table S3†) showed that the intensity of $\mathrm{O}-\mathrm{C}=\mathrm{O}$ peak was reduced and the $\mathrm{C}-\mathrm{O}$ peak shifted to higher binding energy after addition of iron salts to CNF-films pretreated with GA, which indicates that the carboxylic and hydroxyl groups may be involved in an electron transfer process between GA and iron. ${ }^{18}$ The atomic surface composition of the CNF film impregnated with $\mathrm{GA}$ and $\mathrm{Fe}$ salt, i.e. the $\mathrm{C}: \mathrm{Fe}$ ratio, was calculated (Fig. $\mathrm{S} 6 \dagger$ ) from the intensities of the elemental XPS peaks and the individual atomic sensitivity factors. ${ }^{34}$ The $\mathrm{C}: \mathrm{Fe}$ ratio of the films prepared with $\mathrm{Fe}^{\mathrm{II}}$ or $\mathrm{Fe}^{\mathrm{III}}$ was $1: 2.5$ which suggests that the $\mathrm{Fe}^{\mathrm{III} /}$ II ions co-ordinate to at least one and possibly two GA molecules, assuming that the contribution from the underlying CNF films to the XPS signal is relatively small. ${ }^{26,33,34} \mathrm{UV}$-vis

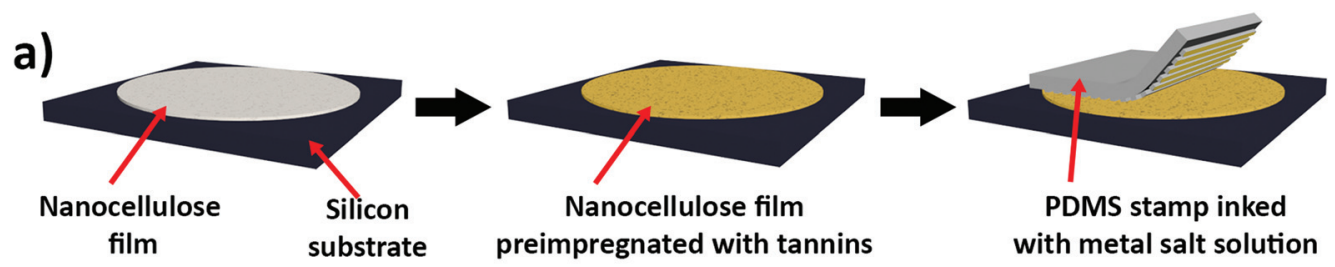

b)
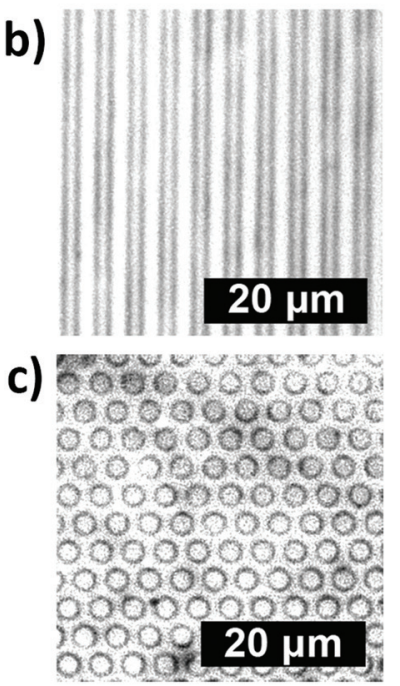
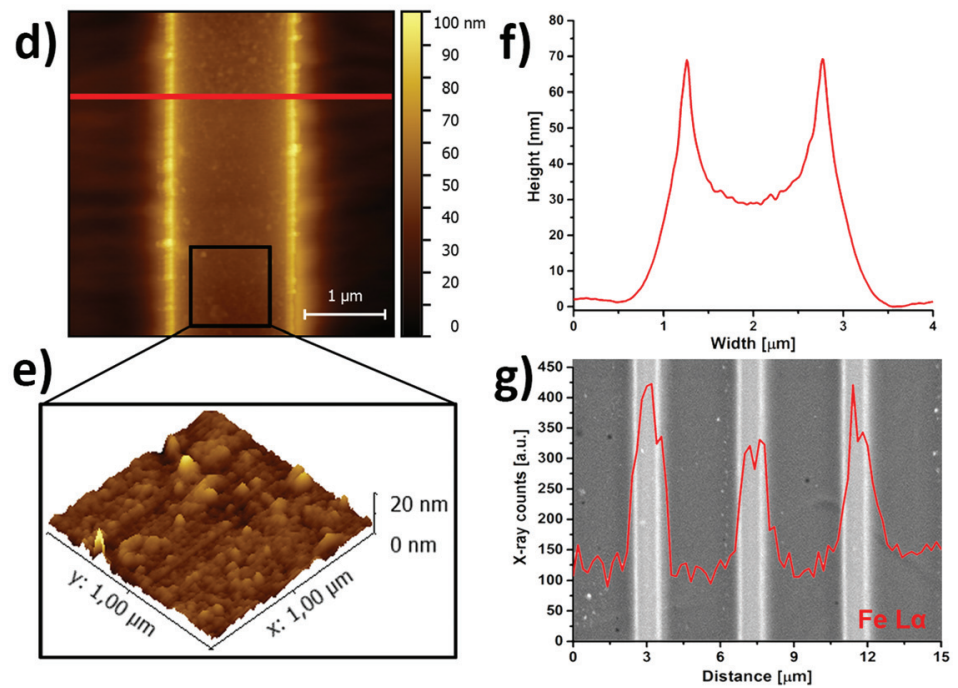

Fig. 3 Patterning of tannic acid (TA)-metal ion nanoparticles onto CNF films. (a) Schematic representation of the impregnation of hydrolyzable tannins and patterning of TA-metal ion nanoparticles on CNF films. Optical grey scale images of CNF films functionalized with TA-Fe"' nanoparticles in: (b) line pattern, (c) dot pattern. (d) Tapping-mode AFM image of line-patterned CNF film. (e) 3D image of the surface of the patterned lines; ( $f$ ) extracted height profiles across one patterned line. (g) Backscattered-electron image with corresponding energy dispersive X-ray (EDX) line scan of CNF film patterned with lines of TA-Fe"l' nanoparticles. 
studies (Fig. S8a and $\mathrm{S} 8 \mathrm{~b}^{\dagger}$ ) showed that the partial reduction of $\mathrm{Fe}^{\mathrm{III}}$ to $\mathrm{Fe}^{\mathrm{II}}$ in a solution of $\mathrm{CNF}$ and $\mathrm{GA}-\mathrm{Fe}^{\mathrm{III}}$ results in a weak absorption shoulder at $\sim 390 \mathrm{~nm}$, which is characteristic for a GA-quinone complex. ${ }^{27,40}$ The surface-bound GA assemblies can also form complexes or nanoparticles with other metal cations. Fig. S9† shows that $\mathrm{Cr}^{\mathrm{III}}, \mathrm{Co}^{\mathrm{II}}$ and $\mathrm{Cu}^{\mathrm{II}}$ metal cations also formed complexes with surface-bound GA assemblies and resulted in functionalized CNF films with colors ranging from dark green $\left(\mathrm{Cr}^{\mathrm{III}}\right)$, brown-red $\left(\mathrm{Co}^{\mathrm{II}}\right)$, and light green $\left(\mathrm{Cu}^{\mathrm{II}}\right)$.

Inspired by the traditional Bogolanfini dyeing technique, ${ }^{12}$ we have used micro-contact printing $(\mu \mathrm{CP})$ to create patterns of iron-tannin complexes on CNF films that had been preimpregnated with a hydrolyzable tannin (Fig. 3a). The printing was performed using a patterned polydimethylsiloxane (PDMS) stamp that had been saturated with a $\mathrm{Fe}^{\mathrm{III}}$ salt solution. The saturated stamp was kept in conformal contact with the pre-impregnated CNF film for an extended time to allow the $\mathrm{Fe}^{\mathrm{III}}$ salt solution to react with the adsorbed TA. After removing the PDMS stamp, micrometer-sized darkly colored line and dot patterns of iron-tannin nanoparticles were obtained on the CNF film (Fig. $3 \mathrm{~b}$ and c respectively). The $\mu \mathrm{CP}$ of surface bound TA-iron nanoparticles on CNF films resulted in printed features with a characteristic size of $\sim 2 \mu \mathrm{m}$, as shown by the tapping-mode AFM image and height profile (Fig. 3d and f). The 3D topographic AFM images of the patterned film suggest that the size of the surface-bound nanoparticles is $\sim 20 \mathrm{~nm}$ (Fig. 3e). The backscattered-electron image with corresponding energy-dispersive X-ray (EDX) line scan confirmed the presence of iron in the patterned lines (Fig. 3g).

The general applicability of the patterning method was further demonstrated using different metal ions, e.g. $\mathrm{Co}^{\mathrm{II}}$ and $\mathrm{Cu}^{\mathrm{II}}$, and another polyphenol (GA), which resulted in red and green colored printed patterns, respectively (Fig. 4a). Hence, $\mu \mathrm{CP}$ of surface-bound polyphenol-metal ion complexes on CNF films is a simple, easy and rapid method that can yield nano/micrometer scale patterns of different colors. The color of catechol- $\mathrm{Fe}^{\mathrm{III}}$ complexes can also be tuned by $\mathrm{pH}$, as demonstrated in Fig. 4b. TA-Fe ${ }^{\mathrm{III}}$ nanoparticles patterned from low $\mathrm{pH} \mathrm{Fe} \mathrm{III}^{\mathrm{III}}$ ion inks were green. Increasing the $\mathrm{pH}$ resulted in red patterns and the color of the patterns could be switched back to green when the $\mathrm{pH}$ is reduced, showing that the color change is reversible. The reversible color change of patterns can be related to the $\mathrm{pH}$-dependent stoichiometry between catecholate-Fe $^{\mathrm{III}}$ complexes. ${ }^{33,41}$ The green TA-Fe ${ }^{\mathrm{III}} 1: 1$ complexes dominate at low $\mathrm{pH}$ while dark red $\mathrm{TA}-\mathrm{Fe}^{\mathrm{III}} 3: 1$ complexes dominate at high $\mathrm{pH}^{33}$

The printed patterns shown in Fig. 3 and 4 demonstrate that $\mu \mathrm{CP}$ of metal ion inks on polyphenol impregnated films can be used to create robust, sub-micrometer-sized patterned nanocellulose films of surface-bound, multivalent metaltannin complexes with tunable color. The Bogolanfini-inspired technique of functionalizing and patterning nanocellulose
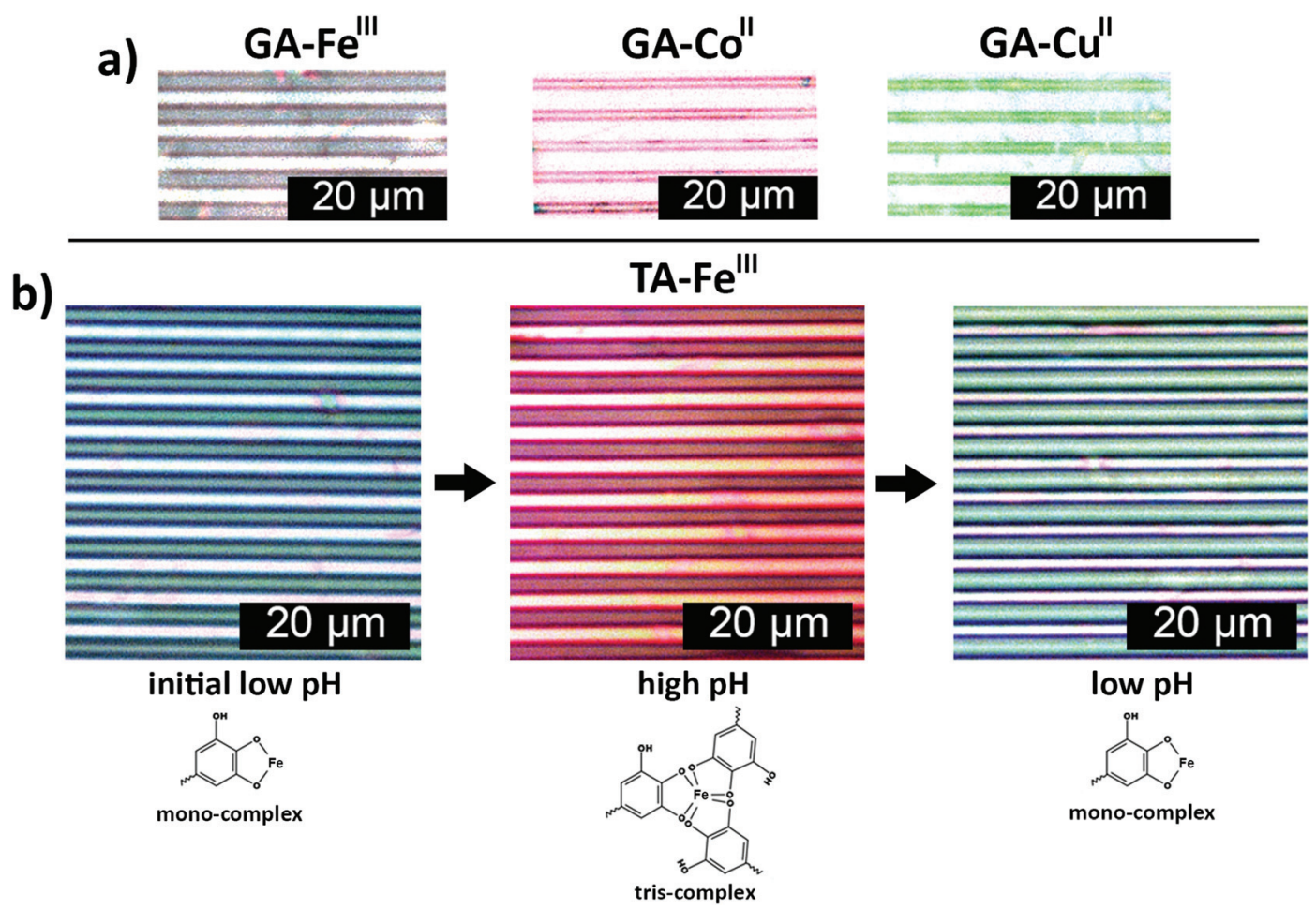

low pH

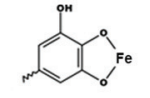

mono-complex

tris-complex

Fig. 4 Tuning the color of hydrolyzable tannin-metal ion nanoparticles patterned on CNF films. (a) Optical images of GA-impregnated CNF films patterned with Fe"I', $\mathrm{CO}^{\prime \prime}$ and $\mathrm{Cu}^{\prime \prime}$ ion salt solutions. (b) $\mathrm{pH}$-Dependent reversible color change and stoichiometry of TA-Fe" complexes patterned on CNF film. 
films could serve as a platform for engineering multifunctional materials for environmental and biomedical applications.

\section{Author contributions}

L.B conceived and lead the study. M.V.L., C.S., G.S.A., K.K. and L.B. designed the experiments. Z.B. and M.V.L. performed and analyzed the IR measurements. M.V.L., C.S. and G.S.A. performed and analyzed the XANES measurements. W.X. performed the XPS measurements. The MD simulations were performed and analyzed by J. W. and M.W. Important insight on the traditional Bogolanfini dyeing technique were provided by M.P. and C.D. The manuscript was prepared by M.V.L., C.S., K. K., G.S.A. and L.B. All authors discussed the results and contributed to finalization of the manuscript.

\section{Conflicts of interest}

There are no conflicts to declare.

\section{Acknowledgements}

The work was financially supported by the Wallenberg Wood Science Center (WWSC) and the Swedish Research Council through Vetenskapsrådet (SE) (award no: 348-2012-6185; L. B.) and Svenska Forskningsrådet Formas (SE) (award no: 9422015-1032; L. B.). MVL would like to thank Department of Science and Technology (DST), India for financial support under DST-INSPIRE Faculty scheme (award no: DST/INSPIRE/ 04/2014/001267). The Max lab, Lund, Sweden is acknowledged for the allocation of beam time under the proposal 20130219 and 20110381 respectively. We also thank Katarina Norén, Kjell Jansson and Tom Willhammar for support during XANES experiments, EDX measurements and photographs respectively.

\section{Notes and references}

1 E. Epstein, M. W. Nabors and B. B. Stowe, Nature, 1967, 216, 547-549.

2 E. S. B. Ferreira, A. N. Hulme, H. McNab and A. Quye, Chem. Soc. Rev., 2004, 33, 329-336.

3 W. J. Russell, Nature, 1894, 49, 374-375.

4 P. Ball, Nature, 2008, 10-13.

5 M. Jose-Yacaman, L. Rendon, J. Arenas and M. C. Serra Puche, Science, 1996, 273, 223-225.

6 L. E. Warren, J. Chem. Educ., 1934, 11, 297-302.

7 F. N. Howes, Kew Bull., 1948, 3, 248-251.

8 R. Siva, Curr. Sci., 2007, 92, 916-925.

9 Y. Ye, L. G. Salmon and G. R. Cass, J. Am. Inst. Conserv., 2000, 39, 245-257.

10 P. S. Vankar, Resonance, 2000, 5, 73-80.
11 V. L. Rovine, Bogolan:Shaping Culture through Cloth in Contemporary Mali, Indiana University Press, 2008.

12 P. J. Imperato and M. Shamir, Afr. Arts, 1970, 3, 32.

13 J. B. Donne, Man, 1973, 8, 104-107.

14 M. V. Limaye, Z. Bacsik, C. Schütz, A. Dembelé, M. Pléa, L. Andersson, G. Salazar-Alvarez and L. Bergström, Text. Res. J., 2012, 82, 1888-1896.

15 A. W. Martinez, S. T. Phillips, M. J. Butte and G. M. Whitesides, Angew. Chem., Int. Ed., 2007, 46, 13181320.

16 W.-J. Lan, E. J. Maxwell, C. Parolo, D. K. Bwambok, A. B. Subramaniam and G. M. Whitesides, Lab Chip, 2013, 13, 4103.

17 H. Liu, H. Qing, Z. Li, Y. L. Han, M. Lin, H. Yang, A. Li, T. J. Lu, F. Li and F. Xu, Mater. Sci. Eng., R, 2017, 112, 122.

18 J. Guo, Y. Ping, H. Ejima, K. Alt, M. Meissner, J. J. Richardson, Y. Yan, K. Peter, D. Von Elverfeldt, C. E. Hagemeyer and F. Caruso, Angew. Chem., Int. Ed., 2014, 53, 5546-5551.

19 H. Ejima, J. J. Richardson and F. Caruso, Nano Today, 2017, 12, 136-148.

20 T. Liu, M. Zhang, W. Liu, X. Zeng, X. Song, X. Yang, X. Zhang and J. Feng, ACS Nano, 2018, 12, 3917-3927.

21 D. Klemm, F. Kramer, S. Moritz, T. Lindström, M. Ankerfors, D. Gray and A. Dorris, Angew. Chem., Int. Ed., 2011, 50, 5438-5466.

22 Q. Yang, H. Fukuzumi, T. Saito, A. Isogai and L. Zhang, Biomacromolecules, 2011, 12, 2766-2771.

23 C. Chen and L. Hu, Acc. Chem. Res., 2018, 51, 3154-3165.

24 K. M. A. Uddin, V. Jokinen, F. Jahangiri, S. Franssila, O. J. Rojas and S. Tuukkanen, Global Challenges, 2019, 3, 1800079.

25 S. Dutta, J. Kim, Y. Ide, J. H. Kim, M. S. A. Hossain, Y. Bando, Y. Yamauchi and K. C. W. Wu, Mater. Horiz., 2017, 4, 522-545.

26 M. A. Rahim, K. Kempe, M. Müllner, H. Ejima, Y. Ju, M. P. van Koeverden, T. Suma, J. A. Braunger, M. G. Leeming, B. F. Abrahams and F. Caruso, Chem. Mater., 2015, 27, 5825-5832.

27 H. Powell and M. Taylor, Aust. J. Chem., 1982, 35, 739-756.

28 T. Zeng, X. Zhang, Y. Guo, H. Niu and Y. Cai, J. Mater. Chem. A, 2014, 2, 14807.

29 A. E. Fazary, M. Taha and Y.-H. Ju, J. Chem. Eng. Data, 2009, $54,35-42$.

30 S. Timofei, W. Schmidt, L. Kurunczi and Z. Simon, Dyes Pigm., 2000, 47, 5-16.

31 Y. Ferrand, M. P. Crump and A. P. Davis, Science, 2007, 318, 619-622.

32 M. Mazik, H. Cavga and P. G. Jones, J. Am. Chem. Soc., 2005, 127, 9045-9052.

33 H. Ejima, J. J. Richardson, K. Liang, J. P. Best, M. P. van Koeverden, G. K. Such, J. Cui and F. Caruso, Science, 2013, 341, 154-157.

34 M. A. Rahim, H. Ejima, K. L. Cho, K. Kempe, M. Müllner, J. P. Best and F. Caruso, Chem. Mater., 2014, 26, 1645-1653. 
35 I. Mohammed-Ziegler and F. Billes, J. Mol. Struct.: THEOCHEM, 2002, 618, 259-265.

36 A. Ponce, L. B. Brostoff, S. K. Gibbons, P. Zavalij, C. Viragh, J. Hooper, S. Alnemrat, K. J. Gaskell and B. Eichhorn, Anal. Chem., 2016, 88, 5152-5158.

37 T. E. Westre, P. Kennepohl, J. G. DeWitt, B. Hedman, K. O. Hodgson and E. I. Solomon, J. Am. Chem. Soc., 1997, 119, 6297-6314.
38 M. Wilke, F. Farges, P. E. Petit, G. E. Brown and F. Martin, Am. Mineral., 2001, 86, 714-730.

39 G. S. Henderson, F. M. F. De Groot and B. J. A. Moulton, Rev. Mineral. Geochem., 2014, 78, 75-138.

40 J. Tofan-Lazar, A. Situm and H. A. Al-Abadleh, J. Phys. Chem. A, 2013, 117, 10368-10380.

41 H. Xu, J. Nishida, W. Ma, H. Wu, M. Kobayashi, H. Otsuka and A. Takahara, ACS Macro Lett., 2012, 1, 457-460. 